Revue

Revue de l'histoire des religions

de Ihistoire

des religions

Jean-Jacques OLIER, L'âme cristal. Des attributs divins en nous, édité, présenté et annoté par Mariel MAZZOCCO, préface de Jacques LE BRUN

Paris, Le Seuil, 2008, 349 p., 21 cm, $20 €$

Stéphane-Marie Morgain

\title{
CpenEdition
}

Journals

Édition électronique

URL : http://journals.openedition.org/rhr/7809

DOI : $10.4000 /$ rhr.7809

ISSN : 2105-2573

Éditeur

Armand Colin

Édition imprimée

Date de publication : 1 septembre 2011

Pagination : 460-462

ISBN : 978-2200-92721-9

ISSN : 0035-1423

Référence électronique

Stéphane-Marie Morgain, « Jean-Jacques OLIER, L'âme cristal. Des attributs divins en nous, édité, présenté et annoté par Mariel MAZZOCCO, préface de Jacques LE BRUN », Revue de l'histoire des religions [En ligne], 3 | 2011, mis en ligne le 09 décembre 2011, consulté le 22 septembre 2020. URL : http://journals.openedition.org/rhr/7809; DOI : https://doi.org/10.4000/rhr.7809

Ce document a été généré automatiquement le 22 septembre 2020

Tous droits réservés 


\section{Jean-Jacques OLIER, L'âme cristal. Des attributs divins en nous, édité, présenté et annoté par Mariel MAZZOCCO, préface de Jacques LE BRUN}

Paris, Le Seuil, 2008, 349 p., $21 \mathrm{~cm}, 20 €$

Stéphane-Marie Morgain

\section{RÉFÉRENCE}

Jean-Jacques Olier, L'âme cristal. Des attributs divins en nous, édité, présenté et annoté par Mariel MAZZOCCO, préface de Jacques LE BRUN, Paris, Le Seuil, 2008, 349 p., $21 \mathrm{~cm}, 20 €$

1 Jean-Jacques Olier (1608-1657) est sans doute plus connu comme fondateur de la Compagnie des prêtres de Saint-Sulpice (1641-1645) et praticien averti de la formation des séminaristes, selon le modèle imposé par la réforme catholique, que comme auteur mystique. Il a pourtant beaucoup écrit, «avec une facilité et une rapidité extraordinaire » constate son premier biographe (p. 21), mais il le fait tardivement. Ses principaux ouvrages datent en effet de la fin de sa vie: Journée chrétienne (1655), Catéchisme chrétien pour la vie intérieure (1656), L'Esprit des cérémonies de la messe (1657) et l'Introduction à la vie et aux vertus chrétiennes qui paraîtront quelques mois après sa mort, sans oublier les Lettres spirituelles et le Traité des saints ordres publiés successivement en 1672 et 1676. Mais on sait, grâce aux études de Jean Gautier (1953) et à l'édition critique établie par Gilles Chaillot, Paul Cochois et Irénée Noye (1984), ce que ce dernier Traité doit à la plume de Louis Tronson.

2 Si l'œuvre mystique de Jean-Jacques Olier est restée dans l'ombre jusqu'au début du $\mathrm{xx}^{\mathrm{e}}$ siècle et l'Histoire littéraire d'Henri Bremond, c'est qu'elle est contemporaine d'une 
orthodoxie sourcilleuse et d'une forte réaction antimystique, dont Jean Orcibal, Jacques Le Brun et d'autres historiens ont dessiné les traits marquants et les effets durables. Les travaux méticuleux de relecture, voire de réécriture, effectués par Louis Tronson sur les écrits de Monsieur Olier, expliquent pourquoi le nom du fondateur des Messieurs de Saint-Sulpice est resté trop longtemps absent de la liste des grands auteurs mystiques du XvII ${ }^{e}$ siècle français.

3 En publiant pour la première fois L'âme cristal, Des attributs divins en nous, Mariel Mazzocco, réintroduit heureusement Monsieur olier dans le courant mystique du Grand Siècle, le plaçant par là même aux côtés de François de Sales, Pierre de Bérulle et Charles de Condren. Dans la ligne de ce dernier, Olier aborde la problématique de l'amour pur de Dieu et de l'amour-propre de l'homme au moment où jésuites et jansénistes s'opposent sur ce sujet. Composé dans les années 1654-1656, le texte Des attributs divins en nous - dont le manuscrit original a disparu, mais dont la copie datant de 1672 se trouve aux Archives de Saint-Sulpice - mérite assurément l'attention des dix-septièmistes et des connaisseurs de l'École bérullienne. Il convient donc de saluer l'initiative de Mariel Mazzocco qui rend justice à un grand auteur français. La belle introduction à cette édition critique, simple et précise, permet au lecteur d'entrer sans crainte dans la lecture de L'âme cristal, malgré l'austérité de l'écriture de Monsieur Olier. Les index des noms et des références bibliques, de même que la bibliographie sommaire (p. 45-47) sont aussi très utiles.

4 Le traité commence par une brève Méthode pour faire l'oraison sur Dieu et sur les attributs divins (p.65-96). Olier divise l'exercice de l'oraison en deux parties: pendant la première, l'âme passe par les états d'adoration, d'admiration, de louange et d'amour ; alors qu'en la seconde, elle entre dans une sorte de communion avec Dieu. «L'âme se voit revêtue de Dieu, pleine de ses attributs et de ses perfections» (p. 87). Cette méthode détaillée doit beaucoup à Benoît de Canfeld et témoigne fortement de la période « néantiste " que traverse Olier en 1644. Il découvre alors « la voie de l'union à Dieu, qui consistait à être dépouillé de tout intérieurement, comme d'images, de fantômes, de goûts, de sentiments, de lumières, et être tellement nu dans le fond de son âme qu'il n'y reste plus rien qu'une capacité pour Dieu » (p. 24 et 87-88). Les attributs divins décrivent cette voie d'anéantissement assimilée à "une glace pure, nue et transparente » (p. 77). Cette voie du double néant - néant de la créature contraire à Dieu, attachée à la chair par le péché, et néant « positif » de l'âme qui, séparée de toutes choses, demeure ouverte pour être remplie de Dieu - rappelle celle enseignée par Bérulle, mais reprise par Condren qui reste la grande référence de Jean-Jacques Olier.

Le portrait de l'homme esquissé par l'auteur a quelque chose de désespérant dans son pessimisme. L'homme est sujet aux passions, aux émotions, aux affects et aux désirs concupiscents. L'homme est pécheur. Mais il est appelé au dépouillement radical pour s'unir à Dieu qui «se baise en l'homme ». "Il ne faut à la communion de Dieu qu'une âme nue et ennemie d'elle-même, une âme anéantie en son fond et qui soupire devant Dieu pour être remplie de lui ; une âme qui est en état de gémissement, en état de soupirs intérieurs vers Dieu, pour attirer sur soi sa plénitude et sa perfection » (p. 92).

6 Une intuition datant de l'été 1651 donne une excellente clé de lecture aux chapitres suivants. Dans son journal, Olier dit avoir appris de la Vierge qu'il est préférable « de regarder les perfections des créatures en Dieu que les perfections de Dieu dans les créatures", car l'âme ainsi "se trouvait plus libre, plus dégagée, plus éclairée et saintement appliquée à Dieu que lorsqu'elle voyait Dieu dans les créatures » (p. 25). 
7 Ainsi, Olier traite d'une manière personnelle, par rapport à l'Aréopagite et à saint Thomas, chaque attribut divin (existence de Dieu, unité, vérité, perfection, infinité, simplicité, sainteté, grandeur, immensité, éternité, science, amour, conformité à la volonté de Dieu, bonté, justice et force), envisagée d'abord en Dieu, puis dans les saints et les bienheureux, et enfin en nous. Il faut que l'âme s'anéantisse pour être pénétrée par ces attributs divins : "Il faut que l'âme soit morte non seulement à toute affection sensible, mais même à toute vue, tous égards et curiosités de la nature; il faut être dénué de ses sens. [...] L'âme ainsi dénuée entre dans ces vastes et immenses espaces de Dieu vérité en lui-même, et entre dans la vue de Dieu tel qu'il est en lui-même. Elle entre en la connaissance de tous ses attributs et perfections immenses qui sont en Dieu lui-même. Et c'est ce gain immense et infini qu'elle fait en quittant la fumée de tout ce monde-ci » (p. 126).

C'est l'état passif décrit par Olier : « qui est quand l'âme reçoit tout purement en elle la participation aux attributs et perfections divines, qui sont simplement les marques de son être et non pas de sa vie. Il faut faire distinction en Dieu de son être et de sa vie, de sa substance et de son opération. L'âme peut être rendue participante des deux " (p. 93). La fin est sublime. Dieu s'aimant en l'âme «aimera purement, saintement, spirituellement, infiniment; bref, aimera dans un vaisseau purifié et dans une puissance libre et dégagée, où, n'ayant rien de bouché par la grossièreté des désirs de la créature, il aimera comme un soleil échaufferait au travers d'un cristal, de même que le feu qui brûlerait au travers du feu et du bois ardant et allumé. Dieu nous fasse la grâce et la miséricorde, par sa vertu et par sa force, de purifier en nous tous nos désirs, de préparer lui-même la place à son amour, et de ne laisser rien en nous qui fasse obstacle à son opération » (p. 240).

Cette édition soignée d'un texte inédit rend incontestablement service aux historiens de la spiritualité. Elle ouvre la voie à d'autres recherches, en particulier celles des sources utilisées par Jean-Jacques Olier, peu mise en lumière ici. Par exemple l'influence de Thérèse d'Avila est-elle directe ou passe-t-elle par la médiation de François de Sales, Ignace n'a-t-il aucune influence sur la méthode d'oraison lorsqu'Olier indique que la "religion chrétienne commence par révérer, par honorer, par louer " (p. 86-87), Bonaventure est-il aussi absent de ses sources littéraires (p. 299-300, n. 307)? Mais l'historien devra aussi se pencher sur l'influence de cette mystique sur les auteurs postérieurs. Il serait enfin utile aussi de passer la théologie mystique de Monsieur Olier au crible de l'Examen de la théologie mystique de Chéron publié en 1657. Ces éléments permettraient sûrement de mieux mettre en lumière la "hardiesse " d'une pensée désormais à la portée de tous.

\section{AUTEUR}

STÉPHANE-MARIE MORGAIN

Institut catholique de Toulouse 